\title{
АЛИФАТИЧЕСКИЕ УГЛЕВОДОРОДЫ В КУКЕРСИТЕ И БЛИЗЛЕЖАЩЕЙ СРЕДЕ
}

Благодаря усовершенствованию аналитических методов в настоящее время удается определять в природных объектах даже ничтожные количества органических соединений, что весьма важно с точки зрения развития геохимии углерода, так как подавляющая масса органического вещества в земной коре находится в рассеянном виде [1'].

Наряду с концентрированными формами (нефтями и другими битумами, битумоидной частью каустобиолитов) алифатические углеводороды в следовых концентрациях присутствуют в самых различных сферах окружающей среды: в воздухе и пыли $\left[{ }^{2,3}\right]$, в природных водах $\left[{ }^{4}\right]$, в известняках $\left[^{5}\right]$ и т. д. В настоящей работе приводятся данные о составе алифатических углеводородов в горючем сланце-кукерсите и в косвенно или непосредственно контактирующих с ним средах (близзалегающих породах, подземных водах).

\section{Методика}

Растворимую в органических растворителях часть исследуемых материалов выделяли экстракцией диэтиловым эфиром (в некоторых случаях также смесью бензола и метилового спирта) в аппарате Сокслета в течение 20 ч. Экстракт после высушивания сульфатом натрия и упаривания растворителя разделяли на групповые компоненты методом тонкослойной хроматографии по методике [6] на силикагеле $L$ (Чехословакия), $100-250$ мкм (элюент - $H$-гексан). Суммарные экстракты и их групповые компоненты анализировались газохроматографически на «Хром-4» с пламенно-ионизационным детектором в условиях программирования температуры (газ-носитель - гелий).

\section{Результаты и обсуждение}

Алифатические углеводороды нормального строения обнаружены в образцах шахтной воды из сланцевой шахты «Кивиыли», отобранных вдали от сланцеперерабатывающего комбината (насосная станция № 1) [7]. Количество экстрагирующихся эфиром органических соедннений в воде составляло $0,05-0,15$ г/ $\Omega$, содержание неароматических углеводородов в экстракте - $15-25 \%$. На рис. 1 приведено распределение $н$-алканов как смолы полукоксования кукерсита, так и шахтных вод в зависи- 


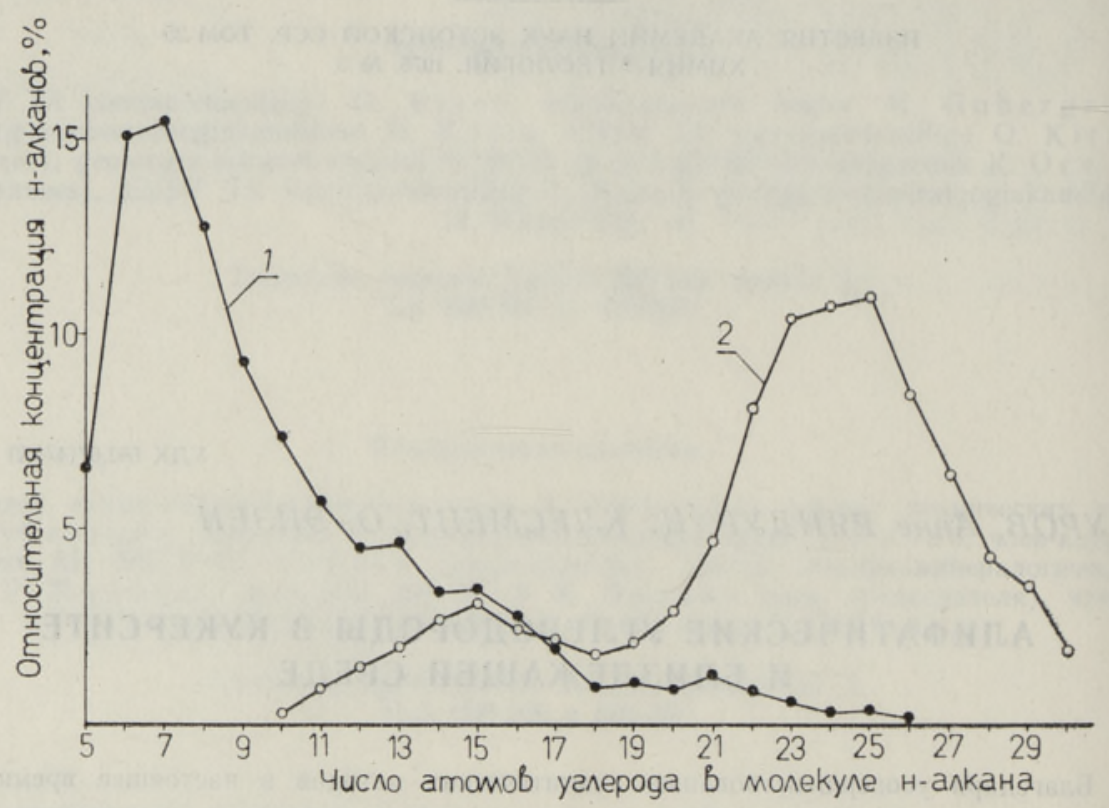

Рис. 1. Распределение $\boldsymbol{н}$-алканов по длине цепи в смоле полукоксования кукерсита (1) и в шахтной воде (2).

Таблица 1

Экстракты керогена кукерсита

\begin{tabular}{|c|c|c|}
\hline \multirow{2}{*}{ Показатели } & \multicolumn{2}{|c|}{ Растворитель } \\
\hline & $\begin{array}{c}\text { Бензол-мети- } \\
\text { ловый спирт } \\
(3: 1)\end{array}$ & $\begin{array}{l}\text { Диэтиловый } \\
\text { эфир }\end{array}$ \\
\hline $\begin{array}{l}\text { Выход экстракта на кероген, \% } \\
\text { Групповой химический состав экстракта, \%: }\end{array}$ & 0,95 & 0,91 \\
\hline $\begin{array}{l}\text { неароматические углеводороды } \\
\text { моноциклические ароматические углеводороды } \\
\text { полициклические ароматические углеводороды } \\
\text { кислородные соединения } \\
\text { Выход неароматических углеводородов на кероген, \% }\end{array}$ & $\begin{array}{l}17 \\
7 \\
4 \\
72 \\
0,16\end{array}$ & $\begin{array}{l}29 \\
11 \\
5 \\
55 \\
0,26\end{array}$ \\
\hline
\end{tabular}

мости от длины углеродной цепи, откуда следует, что занных подземных вод не могут брать начало от смолы термолиза сланца. Известно, что испарение $\boldsymbol{H}$-алканов с длиной цепи более $\mathrm{C}_{12}$ протекает в природных условиях очень медленно [8].

Для получения дополнительных данных о происхождении $\boldsymbol{H}$-алканов в подземных водах была исследована экстрагирующаяся часть керогена сланца. При анализе исходили из концентрата кукерсита, полученного центрифугированием размолотого и обработанного $5 \%$-ной уксусной кислотой сланца из водных растворов хлористого кальция. Характеристика концентрата: $w^{a}=1,9 \%, A^{c}=8,9 \%$; элементный состав керогена: углерода 76,9 , водорода 9,6 , серы 1,8 , азота 0,2 , кислорода +хлора (по разности) $11,5 \%$.

Учитывая отсутствие достаточной определенности в вопросе о наиболее целесообразном составе экстрагента (сообщения о деструктирующем действии четыреххлористого углерода [ [9] и способности спирто-бензольной смеси извлекать наряду с битумоподобными веществами ғуминовые кис- 
a

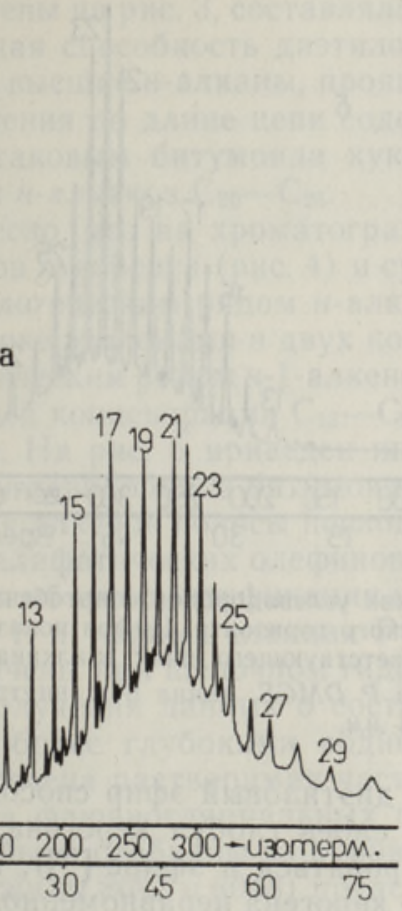

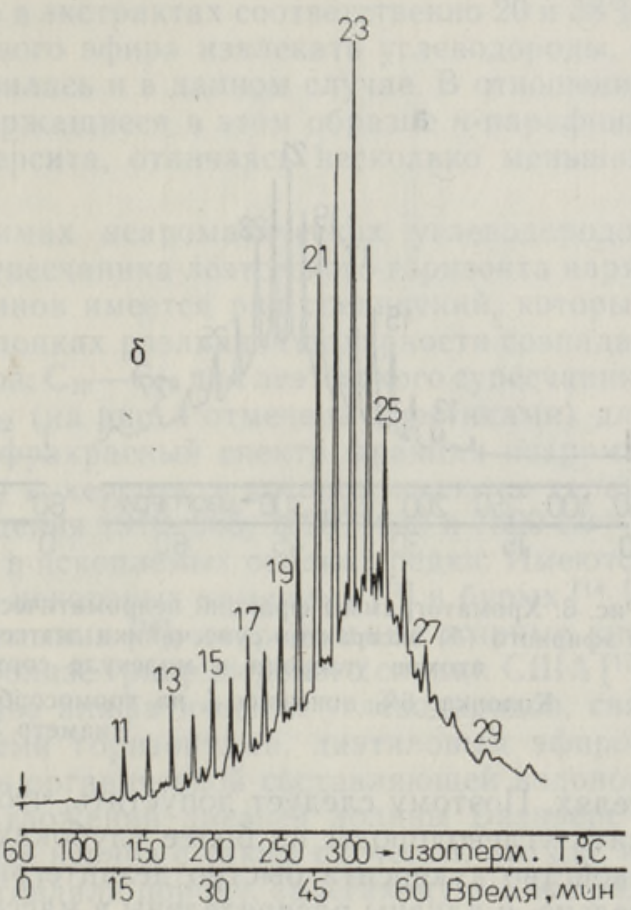

Рис. 2. Хроматограммы фракций неароматических углеводородов спиртобензольного $(a)$ и эфирного (б) экстрактов керогена кукерсита. Цифра показывает число атомов углерода в молекуле соответствующего пику $H$-алкана.

Колонка: $6 \%$ апиезона $L$ на хромосорбе $P$ DMCS, длина 6 м, внутренний диаметр 3 м.s.

лоты $\left.\left[{ }^{10,11}\right]\right)$, экстракцию проводили двумя растворителями: диэтиловым эфиром и смесью бензол-метиловый спирт $(3: 1)$. Характеристика экстрактов дана в табл. 1, хроматограммы фракций неароматических углеводородов приведены на рис. 2.

Из рис. 2 явствует, что в составе алифатических углеводородов битумоида сланца, как и в органической составляющей шахтных вод, преобладают $н$-алканы с длинной $(19-25$ атомов углерода) цепью, что свидетельствует в пользу генетической связи между алканами этих двух контактирующих сред.

Далее, по данным о составе $н$-алканов смолы полукоксования кукерсита (рис. 1) основная масса керогена содержит н-алканы с неразветвленными цепями длиной более $\mathrm{C}_{17}$ в весьма ограниченном количестве, тогда как во фракции алифатических углеводородов экстрактов сланца они играют ведущую роль. Это можно рассматривать как свидетельство происхождения нерастворимой части органической массы сланца и $н$-алкановой фракции его битумонда из разных источников.

И, наконец, из рис. 2 видно, что $H$-алканы эфирного экстракта кукерсита максимальную концентрацию имеют в области $\mathrm{C}_{20}-\mathrm{C}_{25}$, отсутствующую в случае спирто-бензольного экстракта. Благодаря примерно одинаковому выходу экстрактов и более высокому содержанию неароматических углеводородов в эфирном битумоиде с помощью диэтилового эфира из керогена извлекается больше таких углеводородов (табл. 1), и именно за счет $H$-алканов $\mathrm{C}_{20}-\mathrm{C}_{25}$. Указанное явление не обусловлено различной растворимостью алифатических углеводородов в примененных раствори- 
a

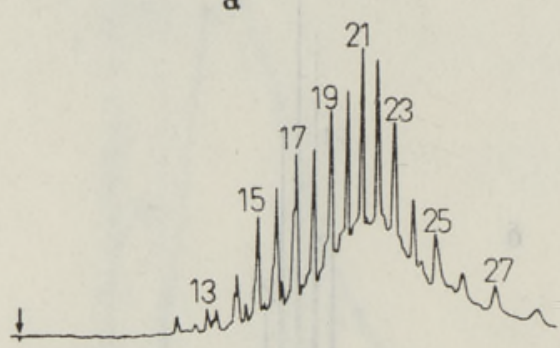

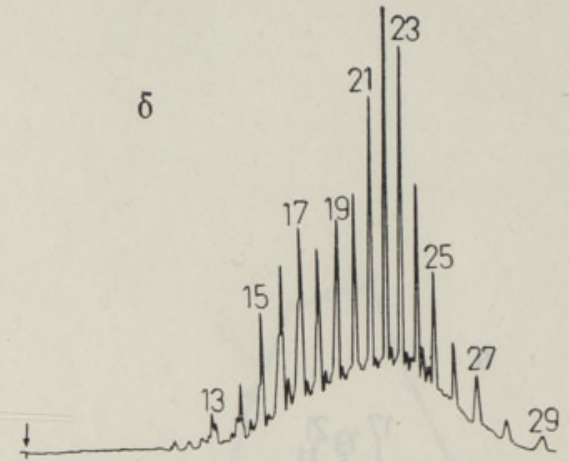

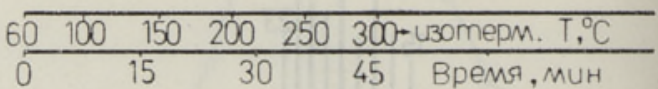

Рис. 3. Хроматограммы фракций неароматических углеводородов спиртобензольного (a) и эфирного (б) экстрактов супесчаника леэтсеского горизонта. Цифра показывает число атомов углерода в молекуле соответствующего пику $\boldsymbol{H}$-алкана.

Колонка: $6 \%$ апиезона $L$ на хромосорбе $P$ DMCS, длина 6 м, внутренний диаметр 3 м.м.

телях. Поэтому следует допустить, что диэтиловый эфир способен извлекать углеводороды из более глубоких слоев глобул керогена (известно свойство кукерсита быстро дезинтегрироваться в эфире [12]), и следовательно, н-алканы распределены в массе керогена неравномерно.

Для сравнения этими же растворителями были извлечены битумоиды из рассеянного органического вещества супесчаника леэтсеского горизонта (образец отобран в обнажении в районе глинта Онтика), омываемого подземными водами, ранее находившимися в контакте с породами вышележащих горизонтов, в том числе и кукрузеского. Выход спирто-бензольного экстракта составлял $0,05 \%$ на породу, эфирного - 0,04\%; содержание неароматических углеводородов, хроматограммы которых

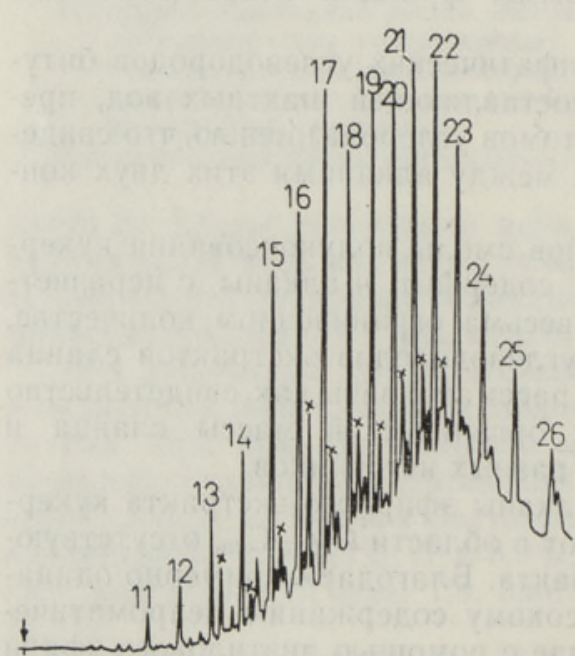

\begin{tabular}{|c|c|c|c|c|}
\hline 50 & 100 & 150 & 200 & 250-uзоmерм. T, ${ }^{\circ} \mathrm{C}$ \\
\hline 5 & 15 & 30 & 45 & 60 Время, MUн \\
\hline
\end{tabular}

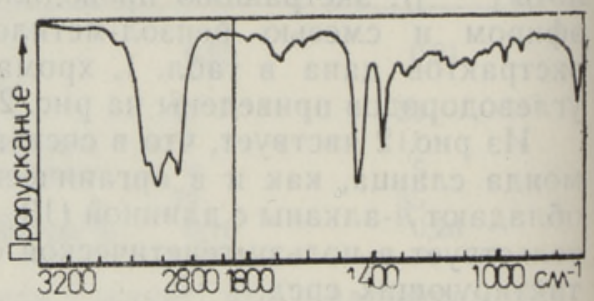

Рис. 5. Инфракрасный спектр фракции неароматических углеводородов спиртобензольного битумоида кукерсита. Спектр снят на спектрофотометре UR-10, призмы из фтористого лития и хлористого натрия.

Рис. 4. Хроматограмма фракции « неароматических углеводородов спиртобензольного экстракта керогена кукерсита. Цифра указывает на число атомов углерода в молекуле соответствующего пику н-алкана.

Колонка: $10 \%$ полиэтиленгликоля 40000 на хромосорбе $P A W$, длина 6 , внутренний диаметр 3 мм 
представлены на рис. 3, составляло в экстрактах соответственно 20 и $38 \%$. Повышенная способность диэтилового эфира извлекать углеводороды, в частности высшие $\boldsymbol{H}$-алканы, проявилась и в данном случае. В отношении распределения по длине цепи содержащиеся в этом образце подобны таковым битумоида кукерсита, отличаясь несколько меньшим значением $\boldsymbol{H}$-алканов $\mathrm{C}_{20}-\mathrm{C}_{25}$.

Интересно, что на хроматограммах неароматических углеводородов битумоидов кукерсита (рис. 4) и супесчаника леэтсеского горизонта наряду с гомологическим рядом н-алканов имеется ряд соединений, который при проверке эталонами в двух колонках различной полярности совпадал с гомологическим рядом $\mathrm{H}$ - 1 -алкенов: $\mathrm{C}_{12}-\mathrm{C}_{19}$ для леэтсеского супесчаника и в меньшей концентрации $\mathrm{C}_{13}-\mathrm{C}_{22}$ (на рис. 4 отмечены крестиками) для кукерсита. На рис. 5 приведен инфракрасный спектр фракции неароматических углеводородов битумоида кукерсита, в котором имеются характерные для алкенов полосы поглощения $\left(910,965,1295,1630\right.$ и $\left.1800 \mathrm{~cm}^{-1}\right)$. Находки алифатических олефинов в ископаемых осадках редки. Имеются сообщения об их идентификации в некоторых каменных $\left[{ }^{13}\right]$ и бурых $\left[{ }^{14,15}\right]$ углях и в т. н. черных сланцах Румынии $\left[{ }^{16}\right]$; непредельные жирные кислоты получены при щелочном гидролизе гринриверского сланца США $\left[{ }^{17}\right]$.

Для получения данных о составе алифатических углеводородов, связанных с более тлубокими водными горизонтами, диэтиловым эфиром была извлечена растворимая часть органической составляющей водоносного песка флювиогляциальных отложений древней долины Вазавере*. Образцы были отобраны из буровых кернов с таким расчетом, что два из них (скважины 8047 и 8048) представляли породу, залегающую ниже размытой в долине (но сохранившейся за коренным склоном долины) пачкн кукерсита, а один (скважина 8064) - выше этого уровня. Данные о выходе и составе экстрактов приведены в табл. 2.

Газохроматографический анализ групповых компонентов экстрактов показал, что по химическому составу углеводороды всех трех битумоидов схожи, и вероятный контакт подземных вод, омывающих песок более глубоких слоев, с кукерситом на состав этой группы соединений значительного влияния не оказывает. Алифатические углеводороды в отложениях

Таблица 2

Выход и состав эфирного экстракта из отложений Вазавереской долины

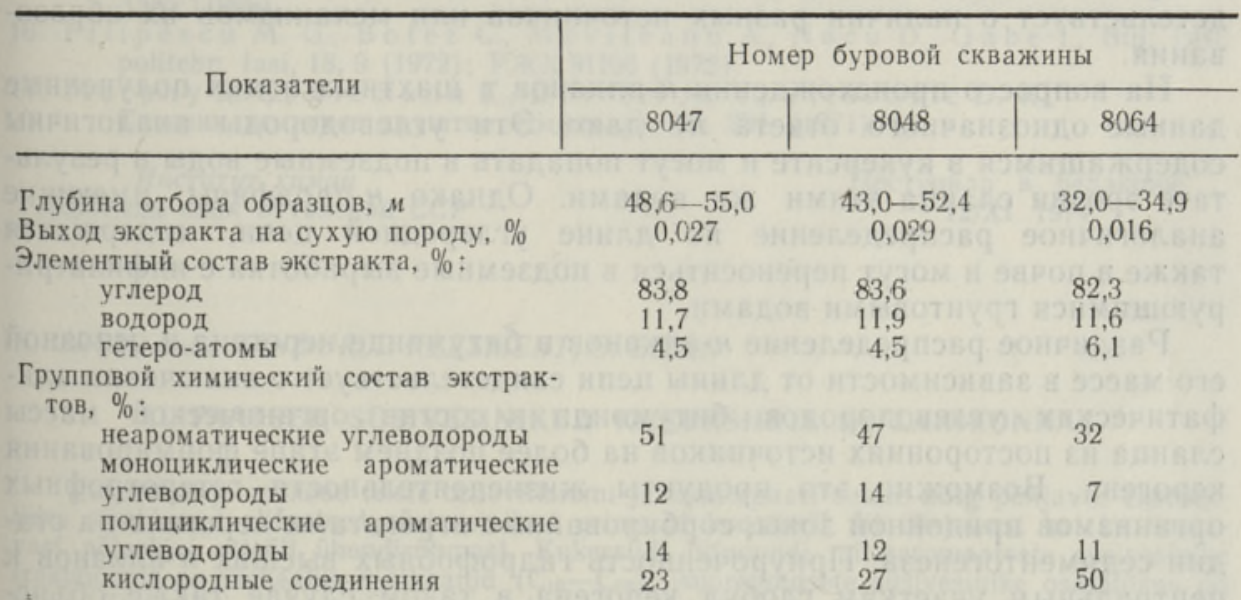

* Образцы были получены при помощи Кохтла-Ярвеской геологической партии. 


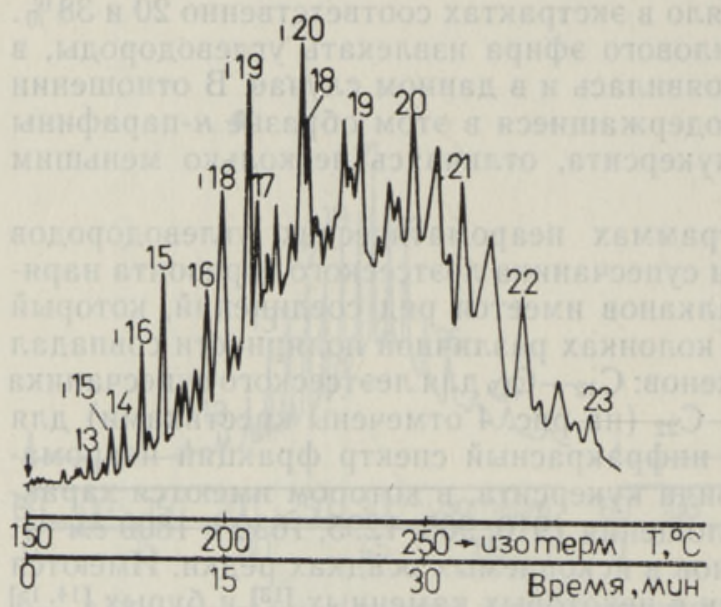

Рис. 6. Хроматограмма фракции неароматических углеводородов экстракта флювиогляциальных отложений Вазавереской долины (скважина 8048) . 13 ..23- н-алканы, $i 15 \ldots i 20$ - изопреноидные углеводороды (i19 - пристан, $i 20$ - фитан). Цифра указывает число атомов углерода в молекуле соответствующего пику углеводорода.

Колонка: $10 \%$ полиэтиленгликоля 40000 на хромосорбе $P A W$. длина 6 м, внутренний диаметр 3 м...

Вазавереской долины по составу коренным образом отличаются от этой же группы соединений в кукерсите, леэтсеском супесчанике и шахтных водах. На рис. 6 приведена хроматограмма фракции неароматических углеводородов одного из экстрактов, откуда явствует, что эта фракция имеет довольно сложный состав, н-алканы играют подчиненную роль, а концентрация изопреноидных углеводородов, особенно пристана и фитана, высока.

Меньше различаются конденсированные ароматические углеводороды битумоида кукерсита и песка Вазавереской долины: в обоих случаях нафталина и его простейших алкилпроизводных обнаружено мало, основная масса этой группы углеводородов приходится на трициклические и более сложные соединения.

Из полученных данных следует, что общей чертой несвязанных алифатических углеводородов кукерсита и близлежащей среды является нали .

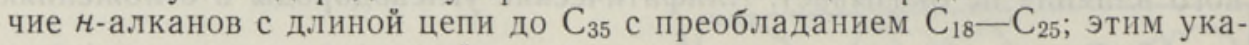
занная группа соединений существенно отличается от углеводородов сланцевой смолы. Однако соотношение неразветвленных и разветвленных алифатических углеводородов в отдельных горизонтах различно, что свидетельствует о наличии разных источников или механизмов их образования.

На вопрос о происхождении $\boldsymbol{H}$-алканов в шахтных водах полученные данные однозначного ответа не дают. Эти углеводороды аналогичны содержащимся в кукерсите и могут попадать в подземные воды в резуль-

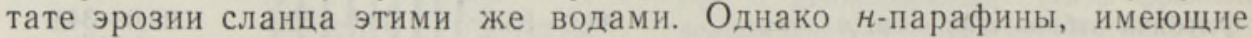
аналогичное распределение по длине углеродной цепи, содержатся также в почве и могут переноситься в подземные выработки с инфильтрирующимися грунтовыми водами.

Различное распределение $\boldsymbol{H}$-алканов в битумоиде керогена и основной его массе в зависимости от длины цепи свидетельствует о включении алифатических углеводородов битумонда в состав органической массы сланца из посторонних источников на более позднем этапе формирования керогена. Возможно, это продукты жизнедеятельности гетеротрофных организмов придонной зоны, сорбированные агрегатами керогена на стадии седиментогенеза. Приуроченность гидрофобных высших $H$-алканов к центральным участкам глобул керогена в таком случае также объяснима. 


\section{Выводы}

1. В составе содержащихся в горючем сланце-кукерсите свободных алифатических углеводородов преобладают $н$-алканы $\left(\mathrm{C}_{10}-\mathrm{C}_{35}\right)$; изопреноидных углеводородов в битумонде кукерсита мало.

2. Углеродные цепи нормального строения в нерастворимой части органической массы кукерсита и н-алканы его битумоида существенні) различаются по длине цепи, что свидетельствует о разных источниках их образования.

3. Получены данные о неравномерном распределении свободных н-алканов в массе агрегатов керогена.

4. Алифатические углеводороды непромышленного происхождения в некоторых ордовикских осадочных породах и четвертичных флювиогляциальных отложениях северной части Әстонской ССР различаются по составу, заметно отличаясь в то же время от соответствующей группы соединений в смоле полукоксования кукерсита.

\section{Л И Т Е Р А Т Р А}

1. В а с сое в и ч Н. Б., В сб.: Природа органического вещества современных и ископаемых осадков, М., 1973, с. 11.

2. Hauser Th. R., P a t t is on J. N., Environment. Sci. Technol,, 6, 549 (1972).

3. Gelpi E., N ooner D. W., Oró J., Geochim, et Cosmochim. Acta, 34, 421 (1970).

4. John so n R. W., C a I d e r J. A., Geochim. et Cosmochim. Acta, 87, 1943 (1973).

5. Nooner D. W., Oró J., Gibert J. M., R a y V. L., M a n n J. E., Geochim. et Cosmochim. Acta, 36, 953 (1972).

6. K lesment I., J. Chromatogr., 95, 705 (1974).

7. У ров К. Э., К лесм н т И. Р., Изв. АН СССР, серня геологич., № 6, 121 (1974).

8. C o le R. D., Nature, 233, 546 (1971).

9. Luts K., Der Estländische Brennschiefer-Kukersit, seine Chemie, Technologie und Analyse, Tartu, 1934.

10. К ар а ваев Н. М., В ал и бек ов Ю. В., Изв. АН СССР, отдел. техн. наук, «Металлургия и топливо», № 2, 146 (1962).

11. К арпенко Н. П., К а ра в а ев Н. М., В ен ер Р. А., Химия твердого топлива, № 6,73 (1967).

12. Лу т с К., Горючие сланцы, 2, 53 (1932).

13. S pence J. A., V a hrman M., Chemistry and Industry, No. 35, 1522 (1965).

14. Sorm F., Woll rab V., Jarolimek P., Streibl M., Chemistry and Industry, No. 44,1833 (1964).

15. Streibl M., Sorm F., Collect. of Czechoslovak Chemical Communications, 31, 1585 (1966).

16. Fil i pescu M. G., B ot e z C., Movile a nu A., N a cu D., G a be I., Bul. Inst. politehn. Iasi, 18, 9 (1972); РЖХ 9П66 (1972).

17. Murphy R. C., Biemann K., Duričić M. V., Vitorović D. K., Гласник хемиског друштва (Београд), 36, 281 (1971).

Ннститут химии

Академии наук Эстонской ССР
Поступила в редакцию 12/XI 1974

K. UROV, Anne RÃNDUR, I. KLESMENT, O. EISEN

\section{ALIFAATSED SUSIVESINIKUD KUKERSIIDIS JA LAXHIKONNAS}

Kukersiidi ja mōnede teiste ordoviitsiumi ja kvaternaari setete ning pōhjavee ekstraktides sisalduvad alifaatsed süsivesinikud erinevad koostiselt nii üksteisest kui ka vastavast põlevkivi utteōli ühendirühmast. Kukersiidi bitumoidi mittearomaatsete süsivesinike fraktsioonis on ülekaalus $n$-alkaanid $\left(C_{10}-C_{35}\right)$, isoprenoidsete süsivesinike osatähtsus on väike. Kukersiidi kerogeeni lahustumatu osa alifaatsete struktuuride ning tema ekstrakti $n$-alkaanide jaotus süsinikahelate pikkuse järgi on erinev. 
K. UROV, Anne RANDUR, I. KLESMENT, O. EISEN

\section{ALIPHATIC HYDROCARBONS IN KUKERSITE-SHALE AND IN THE VICINITY}

Aliphatic fractions of Kukersite-shale, and of some other Ordovician and Quaternary sediments, and aliphatic hydrocarbons, contained in bitumens and underground waters, differ from each other as well as from the shale semicoking oil with regard to their composition. $n$-alkanes $\left(\mathrm{C}_{10}-\mathrm{C}_{35}\right)$ predominate in the non-aromatic fraction of Kukersite bitumen, the concentration of isoprenoid hydrocarbons being low. Distribution of aliphatic structures in the kerogen insoluble part by chain length is different from that of the shale bitumen $n$-alkanes. 